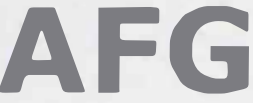

\title{
GEOGRAFÍA E HISTORIA
}

Por: Elsa Ramos

$\mathrm{L}$ os atentados del ll de sepricmbre a las Torres Gemelas en New York y al edificio del Pentágono en Washington, han modificado radicalmente el curso de la historia para los Estados Unidos de: Norteamérica y para todo cl mundo. Los Estados Unidos son en el presente siglo la porencia hegemónica por excelencia, y por ello definen la política mundial directa o indirectamente. L.o grave de éste caso es que por primera vez, éste país ha sido atacado en su territorio nacional, a pesar que cllos consideran el ataque japonés del 7 de diciembre de 1941 a Pearl Harbor como el primero de su historia. Sin embargo, cabe recordar que este puerto queda en el archipićlago filipino, del cual se apoderó EE.UU. al finalizar la guerra hispano norteamericana a principios del siglo $X X$, cuyos principales habitantes son filipinos $y$ que se encuentra ubicado bastante lejos del territorio continental estadounidense. Pero el impacto de éste ataque terrorista a la población y al gobicrno estadounidense es de alcances casi impredecibles: en la medida que ha quedadoal descubierto que también es vulnerable se haborradocl mito de ser la porencia más segura en el mundo.

Despućs de "superado" el asombro y la desorganización momentánca causados por los ataques terroristas, $\mathrm{cl}$ gobierno estadounidense ha incriminado directamente al lider saudi Osama Bin Laden como acror incelectual de dichos atentados. Gil 0 fing basándose en supuestas prucbas que lo ento Entorno

ISSN: 2218-3345

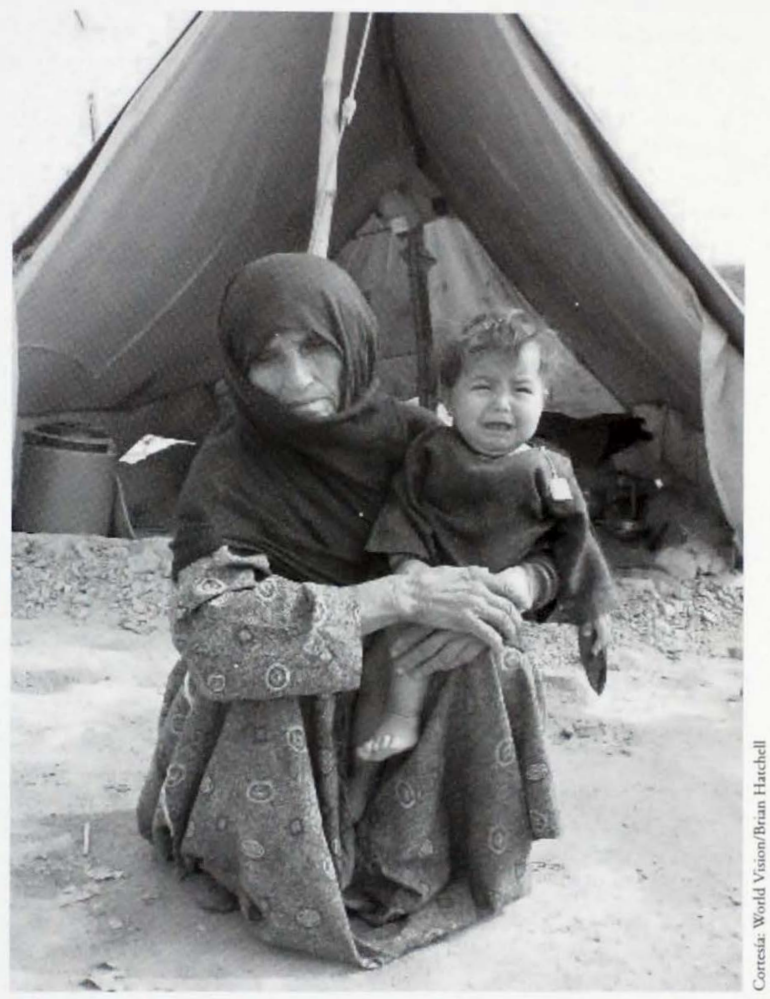

incriminan a ćl y a su organización $\mathrm{Al}$ Qacda. Dichas prucbas aún no son conocidas públicamente, pero amparándose en cllas, Estados Unidos prepara en la forma más cuidadosa un amplio desplicguc militar hacia el
Medio Oriente; hace alusión por primera vez en la historia del artículo quinco de La Organización del Atlántico Norte (OTAN), y busca agenciarse el apoyo diplomácico internacional para formar una amplia 

alianza con sus aliados también con otros palses que no lo son, como la Federación Rusa, la República Popular de China y algunos paises musulmanes. Días después lanza un ataque militar desde el aire al territorio de Afganistán y al régimen Talibán, utilizando y probando lo más moderno de su armamento, incluyendo las bombas BLU - 82 "corta margaritan (con un poder destructivo similar a las bombas atómicas pero

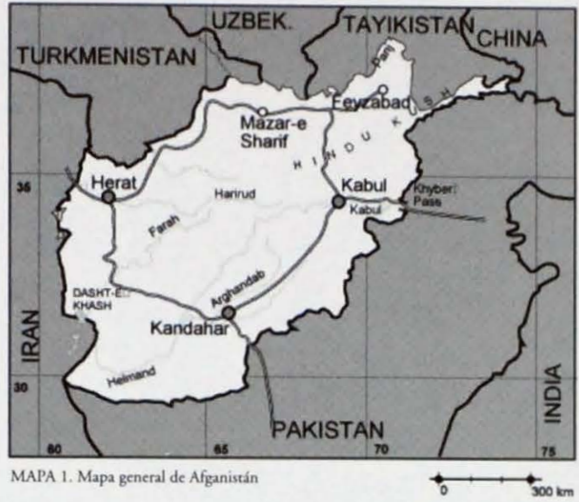

mayoritarios; la religión que profesa la mayoría de la población es el Islam de tendencia sunnita.

Si bien es cierto que la geografía no determina de forma absoluta los destinos de un país, parece que la naturaleza y posición geográfica de Afganistán han incidido sobremanera en éste. Desde el punto de vista geográfico y como ya se mencionó anteriormente, Afganistán, posee una extensión territorial que rebasa los 652 mil kilósin radiación) y las de racimo, estas últimasprohibidas a nivel internacional por los resultados terribles de sus explosiones.

Nadie en su sano juicio aprueba el terrorismo, por ese motivo los atentados del 11 de septiembre acaecidos en el corazón de los Estados Unidos y transmitidos en vivo $y$ a todo color, indiscuriblemente no sólo aterrorizaron a los norteamericanos sino a toda la opinión pública internacional, la que inmediatamente reaccionó condenándolos, solidarizándose con el pueblo y gobierno de ese país. La interrogante acerca de la autoría intelectual de tan funestos acontecimientos adquiría notoriedad. A las pocas horas, el gobierno de los Estados Unidos difundía que el sospechoso principal era Osama Bin Laden y que se estaba trabajando arduamente en reunir las pruebas de su parricipación. Se sospechaba que los autores materiales pertenecían a la organización "Al Qaeda" (La Base), fundada, organizada y financiada en principio por el mismo Bin Laden.

Estados Unidos amenazó públicamente a los autores del atentado $y$ a los paises que les habían dado cobijo, que iban a ser castigados sin compasión. A la fecha ni el régimen Talibán, ni ninguna otra organización de las calificadas como terroristas se han

Entorno

ISSN: 2218-3345 responsabilizado por los atentados del 11 de sepriembre. El gobierno afgano se ha rehusado a entregar a Osama $\mathrm{Bin}$ Laden al gobierno estadounidense. mientras no se presenten las pruebas de su presunta implicación en los hechos. El gobierno norteamericano amparándose en las pruebas que dice poseer, las que supuestamente incriminan a Osama Bin Laden, actualmente refugiado en Afganistán, inició como primer paso un bombardeo masivo el 7 de occubre en contra del territorio afgano.

Para los fines del presente articulo se considera conveniente hacer una breve descripción de la geografía y la historia de Afganistán.

\section{La geografia} ombre oficial: Dowlat - e Eslamiye-Afghanestan Di Afganistan Islami Dawlat. La capital de Afganistán es Kabul y se consideran como ciudades importantes Kandahar, Herat, Mazar1-Sharif y Jalalabad. Su superficie territorial es de $652 \mathrm{mil} 225 \mathrm{~km} 2, y$ la población alcanza los 13 millones 748 mil habitantes (verMapa 1). Se hablan muchas lenguas y dialectos, pero a parrir de 1937 las lenguas acepradas oficialmente son el Dari y el Pashto que pertenecen a los grupos érnicos
$\mathrm{N}$ metros cuadrados, en donde la alcitud promedio de dicho tcrritorio es de mil 200 metros sobre el nivel del mar, está atravesado por altísimas montañas, entre las que se distingue el Hindo Kush, asi como varios desiertos.

Esto indica que por su alcitud, configuración montañosa y la presencia de varios desiertos, el clima de Afganistán es bastante extremo, con temperaturas muy cálidas durante el día, sobre codo en el verano y con descensos bruscos de ellas por las noches, abarida porlos fuertes vientos tanto en la estación de verano como en el invierno, que provocan fuertes cormentas de arena, que impiden cualquicr acrividad humana durance el ciempo que duren. En la estación invernal, las temperaturas normales oscilan entre los $12^{\circ} \mathrm{C}, 22^{\circ}$ y $25^{\circ}$ bajo cero, en las regiones que no están ubicadas a gran alcitud, llegándose a alcanzar los $40^{\circ} \mathrm{C}$ bajo cero en los complejos montañosos.

Afganistán esta enclavada en el corazón de Asia Central, limita el occidente con Irán; al norte con las repúblicas ex soviéticas de Turkmenistán, Uzbekistán y Tadjikistán; al noroeste con la Repuiblica Popular de China (una pequeña franja de 76 kilómetros), al oeste y sur con Pakistán.

Diciembre 2001-Enero 2002,

\section{entorno \\ entorino \\ entorno \\ entorno \\ entorno \\ entorno \\ entortho \\ entorito \\ entorino \\ entorino \\ entomo \\ entorito \\ entorno \\ entorito \\ entorino \\ entorno \\ entoring}

entorina

entorino

enloring

antorino

entoniso

entorino

entomino

entorno

entorino

entorina

entorno

entowino

entorno

entorint

antorin:

enkonio

entorino

entorng

entoring

entorus

Entoras

entorito

entorino

entorno

siftorino

entorino entorino entorno sintorio Antorno entorino aniorng entoring sin(o) 700 
Desde el punto de vista geoestratégico y geopolírico a sí como por las caracteríscicas geográficas sui generis de su territorio, a Afganistán se le ha considerado como la típica tierra "fronterizan, como un "Estado tapón», por el que han pasado numerosas c importantes invasiones, sin nunca poder consolidar un control prolongado sobre el pais.' Dadas las características anteriores, se ha mantenido relativamente aislado, sin mayor influencia culcural y política a pesar de los variados y continuos esfuerzos que realizaron algunos de sus gobernantes durante el siglo XX; por ello su evolución socio-política y cultural se ha mantenido en parámetros "anticuados", de acuerdo al concepto occidental de desarrollo. Otro factor que ha incidido para mantener la situación ya mencionada es la coexistencia de gran diversidad de grupos érnicos, se habla de la existencia de más de cincuenta de ellos así como de lenguas y dialectos. Estos grupos a través de la historia han estado en relativa beligerancia los unos con los otros, pero con la particularidad histórica, de que cuando han sido invadidos, dejan de ladosus diferencias y se unen para expulsar al invasor, aunque después continúen sus luchas internas.

\section{La historia}

entorino entorno

entorno entorno entorno entorho entorno entorno entorno entomo entorno entorno eatorno entorn entorno entorno eutotio entornontorno ents 6

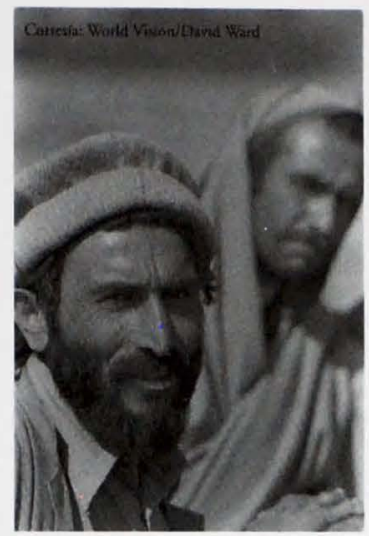

En la antigüedad clásica fue invadido por Alejandro de Macedonia, también conocido como Alcjandro Magno, pero su estancia y huella en el suelo afgano fue efimera como lo fue su imperio. En el siglo XIII fue invadida por Gengis Khan, a quien le cabe la fama de ser el único que pudo conquistar a Afganistán. La siguiente invasión fue realizada por los mongoles en su ruta de conquista de la India, en donde fundaron el imperio mogol allá por el siglo XVI.

En resumen, durante todo el período histórico que en Europa Occidental se conoce como la Edad Media y gran parte de la Edad Moderna, no se puede hablar de un Estado afgano como tal, no es sino hasta el siglo XVIII, cuando un dirigente tribal, Durrani, quién poséa indudablemente grandes y brillantes dores de estadista, logra unificar por primeta vez a las tribus afganas bajo su mando, alcanzando sus dominios hasta la parte norte de la India, antes de ser dividida por los ingleses en 1947, o sea, hasta los límites del actual Pakistán. Con el tiempo y gracias a los conflictos internos, creados por los sucesores de Durrani, el Estado se debilitó y volvió a reinar la dispersión estaacal de las tribus afganas.
Cabe destacar que Afganistán, desde su primera formación como Estado unido, ha sido gobernado en la mayoría de los casos, por gobernantes provenientes de los pashrunes, que son el grupo étnico mayoritatio. Esta particularidad sigue prevaleciendo en la actualidad, ya que los dirigentes Talibán pertenecen a la etnia Pashtun.

Llegado el siglo XIX, Afganistán se encontraba en el punto de mira de dos grandes potencias coloniales: Rusia y el Reino Unido. Este último ya habia logrado poner bajo su dominio a todo el subcontinente indio, $y$ como se sabe para esa época la lndia era considerada como la joya más preciada de la corona inglesa. Inglaterra para hacer menos obvio su avance imperial, actuaba a través de los príncipes indios para tratar de conquistar territorialmente a Afganistán.

Dada la situación de peligro en que se encontraba, por los constantes embates imperiales de Rusia e Inglaterra, se logra reunificar de nueva cuenta el pais. Así, a principios del siglo $X X$. Afganistán logra delimitar claramente sus fronteras con Irán, la India británica y el Impecio Ruso, hecho que en cierta medida, le da al pais una relativa tranquilidad, pero que no logra librarlo de estar bajo la esfera de intereses $\boldsymbol{c}$ influencia de estos tres paises, cada uno de ellos esperando el momento oportuno para apoderarse de parte o sí era posible de todo el pais.

En cuanto a su política exterior, Afganistán se vio somerido a los dictados de Inglaterra, en las últimas décadas del siglo XIX y las primeras del siglo XX.

Durante la Primera Guerra Mundial, Afganistán resistió todas las presiones a que se vio sometido por parte de las diferentes potencias curopeas y el Imperio Turco, para formar parte de alguna de las alianzas políticas y militares que estaban enfrentándose; logrando conservar una politica neutral durante la 
conflagración mundial. Finalizada la Primera Guerra Mundial, en 1919 el gobernante de turno de Afganistán Ilamado Amanullah, declaró la independencia toral del país con respecto a Inglaterra, lo que le costó una guerra con esta potencia; pero siguiendo la tendencia histórica típica del país, todas las tribus afganas unieron fuerzas y lograron derrotar $y$ expulsar a las fuerzas inglesas, firmando un tratado de paz en noviembre de 1921.

Durante la primera mitad del siglo $X X$, el objerivo principal de la política exterior de Afganistán, fue conservar
En las décadas de los 20 y $30 \mathrm{del}$ siglo XX, la polírica interna del país, se esforzó por tratar de modernizar el Estado imitando algunos patrones occidentales y otros de la recién fundada comunidad socialista, entre ellos el sistema administrativo $y$ judicial; se procura planificar la economía, un poco imitando los planes quinquenales adoptados en la URSS; se trata de mejorar la situación de las mujeres afganas, por cjemplo eliminando el tradicional velo (burka), procuraron eliminar ciertos usos $y$ costumbres tribales que ya no estaban a tono con la época y que se consideraba obstaculizaban el desa-

A todo esto en el año de 1933 se establece la monarquía de Zahir Shah que gobernó hasta el año de 1973, fue derrocada mediante un golpe de Estado; es precisamente éste rey, que aún vive en el exilio en Italia, que a la fecha nunca había intentado regresar al pais para retomar el podet, a quien se quiere reinstalar en el gobierno y sustituir junto con otras alianzas al acrual gobierno Talibán.

Duranie la Segunda Guerra Mundial, la posición adoprada por Afganistán, fue bastante parecida a la que adoptó durante la Primera Guerra; se mantuvo lo más apartado posible del eje Roma-Berlín-Tokio, afy

su independencia y de ahí se derivó su neutralidad a nivel político internacional, tratando de mantener un equilibrio en sus relaciones con las tres potencias regionales, o sea, con la Unión de Repúblicas Socialistas Soviéticas (URSS), Irán y el Reino Unido.Siendo de notar que cuandose instaura el régimen socialista en el antiguo imperio ruso, las relaciones entre los dos paises mejoran sustancialmente, estableciéndose lazos de intercambio comercial y cultural.

Entorno ISSN: 2218-3345 rrollo del país, pero parece que las reformas no se hicieron con el debido tacto, por lo que hubo una resistencia feroz a los cambios, tan fuerte que incluso se llegaron a producir levantamientos, lo que obligó al gobierno a dar marcha atrás. Pero algunos cambios se lograron de todas maneras, en 1923 se adopta la primera Constitución afgana, para 1937 se adopta el pasheun. y el darí como lenguas oficiales del país, en 1946 se funda en Kabul la primera universidad, todo lo anterior dentro de una politica nacionalista y modemizante. como de los Aliados, de tal forma que al finalizar ésta, el pais no fue afectado en sus limites $y$ política interna y externa de acuerdo al Nuevo Orden Internacional establecido. Lo que sí influyó de forma importante en su política externa, fue la independencia de India en el año de 1947 y su parrición. surgiendo con ello la República de Pakistán, quedesde el principio fue un fiel aliado de los intereses de la Gran Bretaña. Estos sucesos obligaron a Afganistán a tener un acercamiento casi natural con la URSS, como contrapeso con su nuevo vecino y a los intereses que él representaba en la región.

(...) "Afganistán apoyaba el irredentismo de las tribus pushtun de la colindancia afgano-paquistana en el Noreste del país. El apoyo afgano a un Pusheunistán independiente causó pésimas relaciones con Paquistán, cuyo gobierno le cerró el tránsito comercial a Afganistán a través de su territorion. Recuérdese que Afganistán es un pais mediterráneo, que no tiene salida al mar, por lo que entonces ese cierre de 
fronteras, le causó graves problemas comerciales, que lo encaminaron a fortalecer sus lazos comerciales con Irín y la URSS.

En la segunda posguerra la relaciones entre la URSS y Aiganistan se fortalecicron a tal grado, que cl primero le daba ayuda técnica y militar al cjército atgano, rearmándolo, le asesoraba en la planificación de la economia nacional. sc establecieron intercambios culturales y cientificos. firmaron pactos de amistad y de no agresión. El pais de forma lenta intenta modernizarse, en el ano de 1946 aprucba una nucva constitución política más acorde con los ricmpos que corrian. aparecen diferentes partidos politicos de oposición, a parrir de las clase medias del pais; se realizan las primeras elecciones parlamen-tarias; pero a la par de la relariva liberalización del régimen se dan los movimientos populares de protesta, los movimienros estudianriles de oposición, emergen las primeras organizaciones de izquierda: Khalaq, Parcham y Shulayi Jawed. En las subsiguientes elecciones la izquierda ganaba escaños en el Parla. mento.

El teritorio afgano por sus propias condiciones geográficas, se considera como un pais de alıo riesgo para la agricultura, en donde cada ciereo ticmpo se dan grandes sequias; a principio de la décadia de los serient se produjeron tressequí:s consecurivas, que aunadas al scrio descalabro politico y descuido de la clase politica gobernante que nosupo hacerle liente a los problemas económicos, políticos y sociales del pais, condujeron a un golpe de Estado relativamente pacífico, en contra de la monarquía del Zahir Shah. Es asi como surge la primera repuiblica afgana, la cual lue encabezada por su antiguo primer ministro Muhammad Daud. Las cosas en el pais en lugar de mejorar se empeoraban cada vez mas, el primer ministro aprovechandose de su poder y posición promulga una nueva constirución política, mediante la cual se establece un sistcma politico uniparridista, por supuesto el parrido político al que él pertenecia, estamos hablando de la instauración prácticamente de una dictadura unipersonal y unipartidista, porque en las siguientes elecciones celebradas. le dan el poder nuevamente a Daud por un período de seis años. Las protestas no se hicieron esperar.

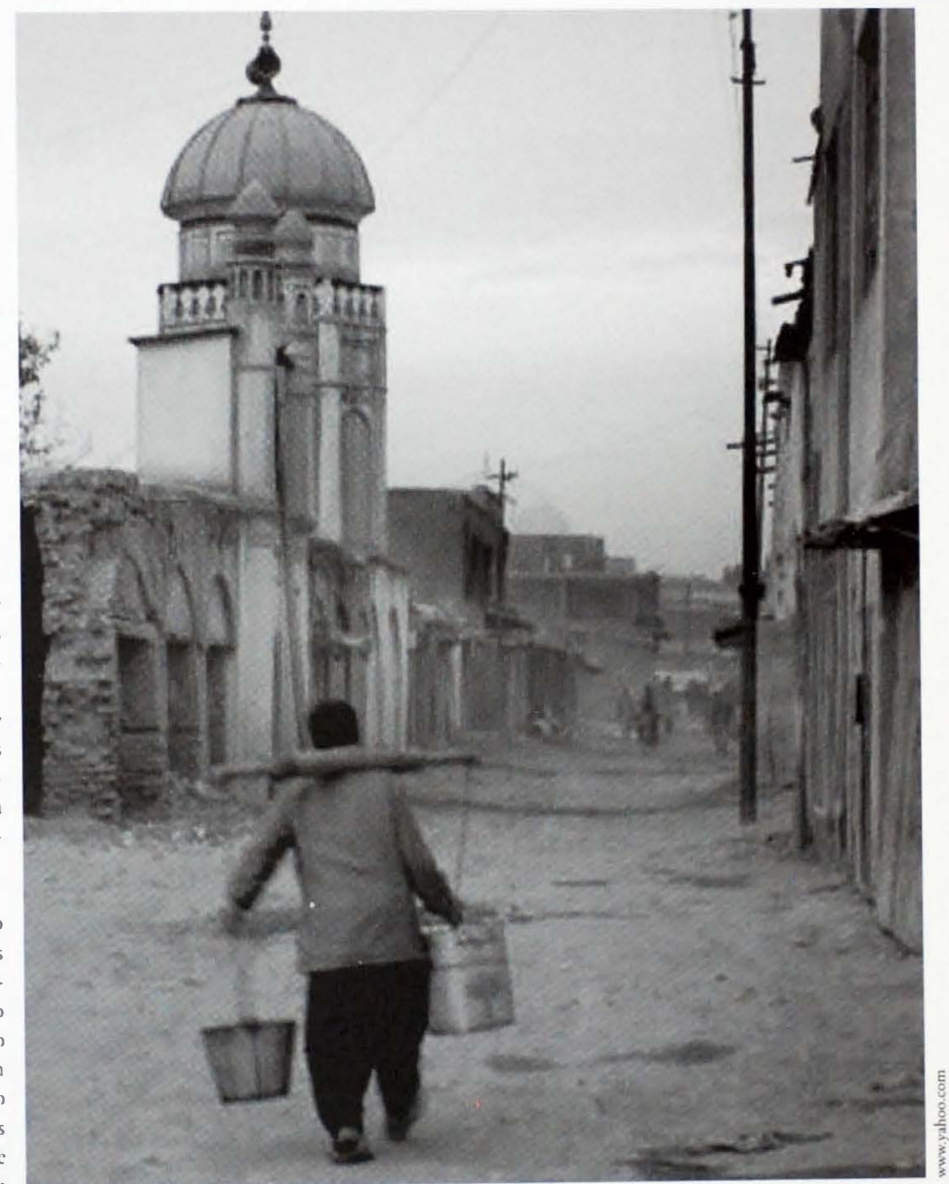


A partir de este momento la vida polírica de Afganistán se convierte en un caos, bastante difícil de comprender. Lo que si de cierto se tiene es que en el ańo de 1978, el partido de izquierda Parrido Popular Democrático llega al poder, pero según parece no estaba preparado para asumir ese cargo, se trato de hacer una serie de reformas socializantes, pero todas fueron un fracaso total, que se ve reflejado en una serie de levantamientos populares, y se incrementa la inmigración hacia Irán y Pakistán. Toda esta con vulsión social conlleva a un nuevo golpe de Estado, es derrocado el líder del partido democrático Nur Muhammad Taraki, su lugar es ocupado por el golpista Hafizullah Amin.

Lo que pasó después es sumamente confuso su explicación, depende de la fuente que se consulte. Las fientes occidentales afirman que Hafizullah Amin, era presionado constantemente por los soviéricos para que realizara reformas, es más afirman que los soviéticos apoyaron al partido Parcham, para que realizara otro golpe de Estado. Como haya sido, la facción Parcham toma el poder en diciembre de 1979 al mando de Babrak Karmal, quién a su vez, al ver lo insostenible que era la situación política, solicita la intervención del Ejército Rojo, para pacificar al país.

La intervención militar soviética duró casi una década, siendo esta la peor derrota recibida por el Ejército Rojo. No sólo perdieron enorme cantidad de armamento, sino que también miles de jóvenes perdieron la vida, otros tantos miles quedaron con estrés postraumático, murilados por las bombas antipersonales colocadas por el mismo ejército soviético y por el movimiento guerrillero en contra de ellos con bombas donadas por los EE.UU., cientos se hicieron adictos a las drogas (hachís y opio).

(....) "Se estima que cerca de 115 mil solados rusos murieron durante la invasión y un número muy superior de

las tropas del gobierno comunista fueron muertos, heridos o desertaron en la larga campaña. Un millón de civiles cayeron vícrimas de la violencia entre ambos bandos en el mismo periodon. ${ }^{4}$

Pero lo peor de todo, aún no ha sido aceptado por el gobierno soviérico en su momento, ni tampoco ahora por el gobierno de la Federación Rusa. Cientos de muchachos soviéticos, llamados cariñosamente por el pueblo "afganos", cuando terminaban su servicio militar destacados en Afganistán y regresaban a sus hogares como veteranos de guerra, sólo regresaban para morir de forma misteriosa, algunos morlan de ataques cardíacos repentinos, cáncer fulminante, extrañas enfermedades de la piel o enfermedades de las vias respiratorias, a soto voce se decia, que tanto el Ejército Rojohabía hecho usode armas químicas y biológicas o que los guerrilleros afganos, también habían hecho uso de ellas, seguramente proporcionadas por los Estados Unidos.

Si trasladamos esa situación al presente y sí es cierto que los guerrilleros afganos utilizaron armas biológicas y químicas en contra del ejército soviérico, lo más seguro es que hayan guardado reservas. En los años de la guerra contra la intervención soviérica los EE.UU. les proporcionaban todo tipo de armamento a manos llenas con tal de que expulsaran a los soviéricos; y no sería extraño que más de algunas de esas reservas se utilizarán cuando se de el ataque terrestre del ejército norteamericano en la presente guerra contra Afganistán.

A los pocos meses de iniciada la intervención militar de los soviéticos en Afganistán, se formaron grupos armad os opositores, que se empezaron a llamar a sl mismos mujaidines (traducido en lenguaje popular quiere decir leones guerreros) empezaron a llamar a las población para que se alzara en una Jihad (Guerra Santa), en contra del invasor soviético. Ninguno de estos dos términos mujaidines y Jihad, son extraños al pueblo afgano, ya que se viene urilizando desde el siglo XVIII, cada vez que el pals era invadido o estaba en peligro de serlo, históricamente ha sido una forma eficaz de unificar las fuerzas vivas del país para expulsar al invasor sea quien sea.

Estados Unidos que estaba furioso por la intervención militar soviética en Afganistán, no podía desaprovechar la oportunidad que se le presentaba al surgir los mujaidines, y a través de la $\mathrm{CIA}$, se establecen los contactos necesarios con estos grupos opositores, a los cuales de inmediato se les empieza a apoyar. Los datos del anterior párrafo son confirmados cuando a los pocos dias de ocurridos los atentados del 11 de septiembre, se empezaron a transmitir una serie de programas televisivos intitulados "Behind the terror. Understanding to the enemyw, en dif erentes canales transmitidos por cable como la CNN en español, el Discovery Chanel, National Geographic, etc.; en donde se puede apreciar una entrevista que se le realizó a Zbigniew Brzezinsky, ex consejero de Seguridad Nacional de Estados Unidos durante la administración de Jimmy Carter; parafraseando lo que él dijo, que una vez enterados de la invasión soviérica, de inmediato el gobierno de los Estados Unidos, pensó que era la hora de edarle su Vier Nam a la Unión Soviérica en Afganistán", que Estados Unidos había cometido un grave error al haber dejado a la deriva a Afganistán $y$ a los afganos una vez expulsados los soviéricos.

A los pocos meses de iniciada la intervención soviética, ésta ya se habia empantanado; las causas fundamentales de dichoempantanamiento tienen origen diferente.

En primer lugar, el Ejército Rojo no estaba peleando una batalla que convenciera a los jóvenes soldados. no había entrega, espíritu de sacrificio,

entorno

entorno

entorno

entorno

entorno

entorno

entorno

Entorino

entorns

entorno 
compromiso real con la causa afgana, no cstaban peleando por su ticrra y para su tierra. Estaban en un territorio completamente desconocido para ellos y con una geografia completamente accidentada por naturalcta, aparte que no cra una guerra regular, los soldados se ven obligados a hacerle frente a una tácrica guerrillera, con gente que peleaba por su país, excelentemente armados. EE.UU. c Inglaterra se habian preocupado en proporcionales armamento sofisticado como los cohetes red-cye, cuya caracteristica fundamental es que persigue su objecivo, coheces Stinger que pueden alcanzar objetivos a 3 kilómetros de distancia; es decir que, la guerrilla tenia lo mejor en ese momento para derribar helicópteros, que es el transporte ideal para el descmbarco de tropas en terrenos de difícil acceso.

En segundo lugar, el supuesto cjército regular afgano, como tal dejaba mucho que desear. Debía ser entrenado, pertrechado y supervisado por los soviéticos ante su baja capacidad militar. Este ejército paulatinamente se empezó a desmoronar, sobre todo por cl altogrado de deserción, cortupción, a tal punto que el último periodo de la intervención soviérica, las acciones militares estaban casi en su totalidad en manos del Ejército Rojo.

En tercer lugar, el gobierno republicano norteamericano de Ronald Reagan (1981-1988), promovió una política de recrudecimiento de la guerra fría, le da un gran impulso al Complejo Militar Industrial (CMI), para sustentar la nucva estrategia de defensa llamada la "Guerra de las Galaxias". Uno de los primeros posculados de la politica exterior del gobierno de Reagan fue la declaración pública, que "su gobierno no iba a permitir que ni un metro más de territorio del mundo libre, cayera en manos del comunismo". Reagan criticaba acremente a su antecesor Jimmy Carter, por no habcr sido capaz, según él, de detener la Revolución Islámica liderada por el Ayatollah Jomeini en Irán en 1978. El nucvo gobierno iraní inmediatamente declaró a EE.UU, como el enemigo principal de la revolución iraní y de todo cl mundo musulmán. Sucedió la crisis de los rehenes norteamericanos en la embajada en Teherán, que no fue resulta por el gobicrno de Jimmy Carter. En América Latina, el patio trasero de EE.UU, las gestiones promovidas por éste último ante la OEA para formar un contingente militar bajo la bandera de ésta organización para invadir Nicaragua fracasó. Por única vez los cancilleres latinoamericanos le dijeron que no a los EE.UU, se pronunciaron a favor de que fuera el pueblo nicaragiense el que decidiera, quien lo gobernaria. No hay que olvidar que éste pais había estado bajo una dictadura militar impuesta por los EE.UU. desde 1934. Gracias en parte a esta negativa pudo triunfar la Revolución Sandinista, la que por su misma naturaleza politica c ideológica, establece relaciones diplomáticas con todos los paises, incluyendo a Cuba, la República Popular China y con todos los paises del bloque socialista de Europa Oriental. Estados Unidos sinció que su patio trasero estaba siendo invadido por la URSS.

Para agravar la situación, en El Salvador a finales de los secenta, era eminentemente el inicio de una guerra

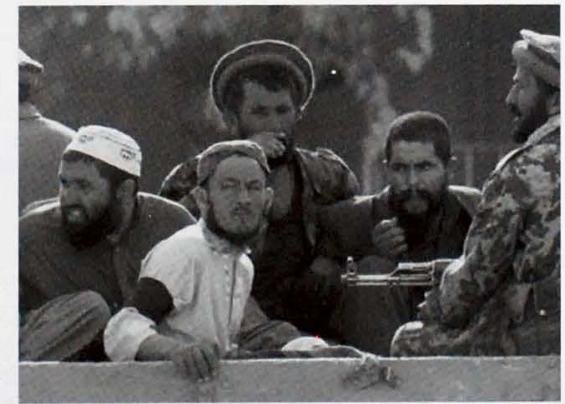

civil, en conera de los regímenes militares de derecha que habían gobernado al país desde los años $30 \mathrm{del}$ siglo XX. Reagan se estaba imaginando que toda la región centroamericana iba a ser presa de revoluciones sociales simpatizantes del comunismo.

Es precisamente en este contexto internacional, del supuesto avance del comunismo y del fundamentalismo en cl Cercano Oriente que, Ronald Reagan asume el poder, y para cumplir su promesa de no cederle un metro más al comunismo discña una seric de medidas de polícica exterior. Para América Latina y en especial para la región Centroamericana se diseña la políica del "Roll Back", que iba a ser permicida por la aplicación de la "Guerra de Baja Intensidad". Comose aplicó ya es historia conocida.

Retomando el caso que interesa, la pol ícica de Ronald Reagan en cl caso de Afganistán, fue apoyar con todos los medios y recursos a los opositores del Régimen de Babrak Karmal y de la presencia militar soviérica en el pais. La CLA actuó libremente, para reclutar, entrenar y financiar a los opositores a ese régimen. De esa forma los campos de refugiados en Pakistán c Irán se convirticron en las bases de reclutamiento y logística de los mujaidines, en la Guerra Santa (Jihad), que se declaró en contra de los soviéricos.

A parcir de la revolución fundamentalista en Irán, ésta corriente moderna del radicalismo religioso musulmán, se difunde por Africa del Norte, el Cercano y Medio Oriente así como el los países del Asia Central. Surgen diferentes agrupaciones fundamentalista como el Hezbollah. el Hamaz y la Jihad Islámica. En cada país tiene nombre diferente pero en general su esencia es la misma: en nombre del Islam se cnarbolan objecivos polícicos 
Afganistán: geografia e historia

de diferente indole, unos en contra del imperialismo norteamericano, otros en contra de la política expansionista de Israel en los territorios palestinos, etc., lo que difiereen ellos son los métodos utilizados para alcanzar sus objecivos, $y$ no necesariamente todos usan el terrorismo a ultranza como mérodo.

Precisamente al difundirse el fundamentalismo Islámico, la CIA encuentra diferentes países en donde reclutar voluntarios para luchar en Afganistán en contra de la intervención soviérica. Es precisamente en éste contexto en donde surge Osama Bin Laden, multimillonario saudita, que en un principio era el encargado de recaudar fondos entre los gobiernos y millonarios del Golfo para la causa Afgana; con el tiempo se involucra más profundamente en el problema afgano. Para ello se traslada a Pakistán y se da cuenta que toda la organización para ayudar a la lucha armada afgana es de una precariedad increíble. Decide tomar en sus manosla organización de dicha ayuda, rápidamente se ven los resultados, de ser una organización amorfa, se transforma en una red bien organizada de recaudación de fondos, reclutamiento de voluntarios, hasta organizar la logistica de los ataques militares desde Pakistán y dentro de Afganistán.

Todas estas operaciones eran totalmente apoyadas por la $\mathrm{ClA}$. Se dice que la red organizada entre Osama Bin Laden y la CIA, logra reclutar voluntarios para la lucha afgana en más de 40 paises diferentes. Osama Bin Laden era muy querido y estimado por el gobierno de los Estados Unidos y de su propio pais, Arabia Saudita. Es más, se sabe a través de muchos medios, que la compañía constructora perteneciente a la familia Bin Laden, recibió la licitación para remozar las mezquitas más importantes de ese país, en agradecimiento a la labor de Osama Bin Laden.

Entorno

ISSN: 2218-3345

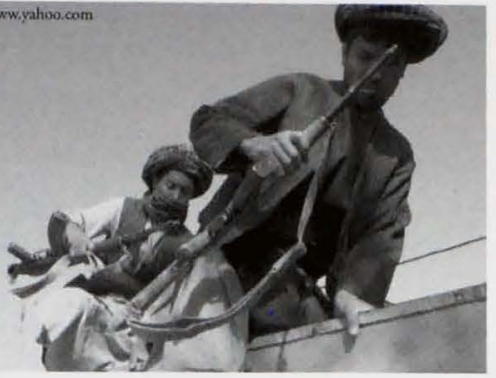

las tropas soviéticas se inicia en el mes siguiente y se da por finalizado el 15 de febrero de 1989.

Como resultado de una década de guerra en Afganistán, el país quedó casi en ruinas su capital Kabul, se transformó en una ciudad sobrepoblada por la inmigración de los escenarios de guerra del interior del país hacia la capital, alcanzando ésta aproximadamente los dos

Por último, la misma Unión Soviérica estaba pasando, por duros momentos, los errores cometidos en la dirección de asuntos internos del país, más el gasto desorbitados en la carrera armamentista con los Estados Unidos, no le había permitido al país gozar de todos los beneficios de la Revolución Científico-Técnica; no se produjo la esperada reconversión industrial en el país, la economía no creció en los niveles esperados para realmente ponerse a la altura de la competencia con el mundo capitalista, todo ello renía muy molesta a la población soviética.

A la muerte de Chernenko, Secretario General del Partido Comunista de la Unión Soviérica (PCUS), accede al poder un hombre joven y con ideas renovadoras Mijail Gorvachov, que a los poco meses de su ascenso al poder promulga los decretos de la Glassnost y la Perestroika, que no sólo propone realizar cambios sustanciales en la política interna del país, sino también en la política exterior. Con la apertura y la flexibilización de la política exterior es que su gobierno comprende, aunque no admite abiertamente la inutilidad de la intervención militar de la URSS en Afganistán; es así como se dan todos los pasos necesarios para retirar todo el contingente militar de ese país. En abril de 1988 se firma un acuerdo de paz, mediante el cual se acuerda el retiro de las tropas soviéticas, el cese de la ayuda militar de Occidente a los rebeldes afganos y un alto al fuego en todo el país. El proceso del retiro de millones de habitantes; la mayoría de sus profesionales se habian exiliado, la poca infraestructura vial con que contaba el país queda semidestruida. Millones de inmigrantes afganos no regresan nunca más al país, quedándose en los paises que les ofrecieron asilo. La agricultura y la ganadería no se pueden reanudar con normalidad, pues loscampos quedaron minados, se habla de 10 millones de minas antipersonales colocadas tanto por las tropas soviéticas como por los movimientos guerrilleros antisoviéticos. Retiradas las tropas soviéticas, objetivo que buscaba, los EE.UU. no cumple sus promesas de ayudar económicamente al país para superar los problemas de la posguerra, tampoco brinda su apoyo científico $y$ técnico; en pocas palabras Afganistán es abandonado a su suerte.

Finalizado el retiro de las tropas soviéticas, el poder político en Afganistán es asumido por un Consejo Supremo Militar, se nombra como presidente a Mohamed Najibullah; sin embargo la situación política sigue siendo inestable, las diferentes facciones militares que lucharon contra la ocupación sovićtica luchan entre sípor apoderarse de la mayor cantidad de armamenco abandonado por los soviéricos así como dominar la mayor cantidad de provincias para sí.

En el mes de noviembre de 1990. el presidente Mohamed Najibullah se reúne en Ginebra, con los Iideres rebeldes de las fracciones más importantes, con el objetivo de llegar 
a un acuerdo que ponga fin a la guerra civil en Afganistán. Se firma el acuerdo, pero al poco tiempo se rompe la tregua. En abril de 1992 se forma un consejo rebelde de 50 miembros (Shura), para gobernar interinamente al pals y preparar elecciones democráricas, sin embargo las acciones armadas continuaron, todos se quieren apoderar de Kabul.

Es en este ambiente de caos político que en 1994, surge el Movimiento Talibán (textualmente estudiantes del Corán), en Pakistán en las Madrazas (escuelas del Corán), y en Afganistán (Kandahar y Herat) en los campos de refugiados, se dice que la mayoría de sus miembros pertenecen al grupo érnico de los pashtun.

¿Quiénes son los talibán? Talibán es el plural de la palabra persa "telebch", que puede traducirse como buscador de la verdad.

Los talibán surgieron de las escuelas coránicas (madrazas) de Kandahar (Afganiscán) y Karachi y Lahore (Pakistán). Esta milicia estaba formada por jóvenes de confesión suní, mayoritaria en Afganistán, y fueron apoyados por Estados Unidos, Arabia Saudi y Pakistán en la guerra civil que siguió a la derrota soviérica en 1989. Los talibán propugnan una interpretación muy rígida del islam y contra la inserción de la mujer en la vida social. Bin Laden, a quien Estados Unidos responsabiliza ahora de los atentados de Nueva York y Washington, formó parte de los grupos islámicos que en los años ochenta recibieron millones de dólares por parte de Estados Unidos para luchar contra las tropas soviéricas.

De acuerdo a los datos aportados por la ex primera ministra de Pakistán Benazir Bhutto, en entrevista que le realizó Donna Foote del Newsweek dice: *Los talibanes eran, en realidad estudiantes universitarios que decidieron volver a Afganistán después que los rusos se marcharon. Según mis reportes, eran bien recibidos y estaban instaurando la paz. Inicialmente, pensamos queel Talibán era una fuerza estabilizadora. Mi gobierno estaba ansioso por establecer vinculos con Asia Central $y$, por eso, nos sentimos complacidos y los estimulamos. Nosotros queríamos importar trigo y exportar algodón a Asia Central, y deseábamos una ruca que nos diera apoyar a los talibanes de la tendencia sunnita a tomar el poder en Afganistán: se quitaban el dolor de cabeza de una Irán Shíta y fundamentalista, además los talibanes les proporcionarían seguridad a sus convoy comerciales; se quitaban el problema de un Pashunistán? beligerante. Con todo lo anterior el gobierno paquistaní se podría dedicar tranquilamente al problema de Cachemira, aún no resuelto con la India desde 1947; sin hablar de los

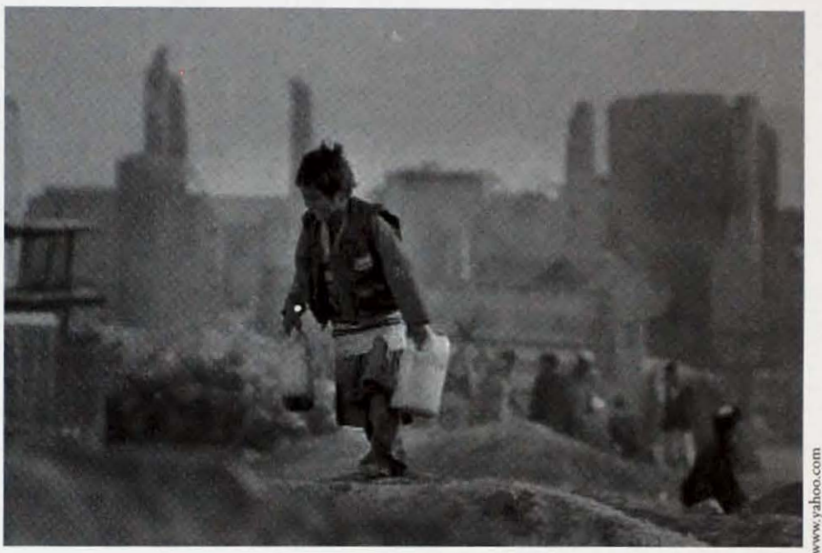

acceso pasando por Kandahar (donde se encuentra la sede del Talibán). Estabamos tratando de evitar pasar por Kabul y establecer un enclave en el sur. Se suponía que los talibanes nos darian un salvoconducron.6

Más adelante en la misma entrevista, Benazir Bhutto añade: “Al principio, les dimos respaldo político y diplomácico. Asimismo, les proporcionamos combustible, alimentos, comunicaciones y transporte. Los talibanes prosperaron, y nosotros los apoyamos porque los vimos como una vía para nuestros intereses económicos con respecto a Asia Central."

Lo que se le olvida a Benazir Bhutro, es mencionar los beneficios geopolíticos que pretendían obtener al beneficios de el narcorráfico, cuestión de la que se tratará más adelante.

Así, con el apoyo paquistaní, los talibanes ya para febrero de 1995 avanzan al centro del país, expulsando al primer ministro, durante todo el año de 1995 y parte de 1996 bombardean constantemente Kabul, la que cae en sus manos el 27 de sepriembre de 1996. siendo su primer acto político desde el poder, el fusilamiento de Mohamed Najibullah. Otro acto político importante de ellos en junio de 1997. es el cierre de la embajada iraní en Kabul, bajo el pretexto de que «Irán contribuía a la discordia entre los afganosn; cuestión que no es del todo falsa, ya que la mayoría de los refugiados que acogió Irán durante la intervención soviérica y los que se 
agregaron como producto de la guerra civil eran de origen érnico Hazara, de ascendencia iraní, a los cuales no sólo les dio refugió sino que también los armó y sigue apoyando a la fecha en contra de lostalibanes. El acto anterior también estaba en concordancia con lo que esperaba de ellos Pakistán.

Para empeorar la situación del pueblo af gano presa de una cruenta guerra civil, en agosto de 1997, se decreta una crisis alimentaria por la constante sequila que azota el país, amen de que los agricultores $y$ ganaderos no pueden trabajar. A ello se van a sumar dos grandes terremotos en 1998, sucesos que no impidieron que los talibanes continuaran su of ensiva en contra de sus opositores.

Para mediados de 1998 la Shura de Ulemas, a través del mulá Mohammad Omar, decretan la supresión de codos los partidos políticos; se prohibe la posesión de aparatos eléctricos de comunicación, como televisores, radios, videocasseteras, grabadoras, antenas parabólicas, erc., miles de esos apararos son destruidos. Se establece la rLey del Talión" para castigar los delitos. A las mujeres y a las niñas se les recluye en sus casas, de las cuales no podían salir sin la compañía de un miembro masculino de la familia, se les prohibe utilizar cualquier tipo de cosmérico, se les obliga a usar la burka fisera de la casa y además se les prohibe tener acceso a la educación y a la medicina. Cabe aclarar, que todas esas medidas no responden al Islam, el cual nunca ha antepuesto la fe a la razón, sino más bien a la práctica de costumbres tribales ancestrales y caídas ya casi en el olvido, pero revividas por el régimen Talibán.

Para principios de agosto de 1998. el 90 por ciento del territorio afgano esta en poder de los talibanes, quedando el otro 10 por ciento en manos de fuerzas opositoras, que hoy en día se hacen llamar la Alianza del Norte y cuyos dirigentes y miembros

Entorno ISSN: 2218-3345 pertenecen a la minoría étnica de los uzbekos y tadjikos. "Los talibanes (...) Son el fruto envenenado de la guerra civil combatida en la última fase de la guerra fría. En ésta, la CIA, junto al servicio secreto paquistaní, ISI - Inter Service Intelligence - organizaron la que fue definida como la más grande acción encubierta en la historia de los servicios, alimentando, financiando, entrenando y respaldando la Jihad guerra santa - islámica de los mujahidin contra la invasión soviérica». ${ }^{8}$

A medida que han pasado los años, el régimen Talibán ha perdido la simpatía de propios y extraños, la ONU lo ha condenado reperidamente asi como otras organizaciones internacionales en defensa de los derechos humanos, organizaciones feministas; por todas las atrocidades que cometen contra su propio pueblo $y$ en especial en contra de sus mujeres; por la transgresión a las normas de la convivencia internacional, a tal punto que antes de los atentados del 11 de septiembre sólo tres gobiernos lo reconocían, Pakistán, Arabia Saudita y los Emiratos Arabes Unidos. Después del 11 de septiembre, sólo Pakistán siguió sosteniendo relaciones diplomáticas con Kabul, canal que han aprovechado los talibanes para dar a conocer la posición de su gobierno ante el ataque de los Estados Unidos, pero a partir del 7 de noviembre el régimen pakistaní prohibió que los embajadores talibanes continúen con sus conferencias de prensa habituales.

\section{La Geopolítica del narcotráfico y el petróleo}

A fganistán es un de los pueblos más pobres del mundo, se sabe que su ingreso per cápita anual es de sólo 220 dólares norteamericanos, carece de industria, su ganadería y agricultura están en completa decadencia, por ef ecto de la guerra (campos minados $y$ deforestados, sus sistemas de regadio fueron destruidos por la guerra) a lo que se ha aunado más de tres años de sequía continua. Se sabe que cuenta con riquezas naturales que no han sido exploradas por las mismas causas. Además posee ricos yacimientos de piedras preciosas y semipreciosas; en la parte norte de su territorio se encuentran ricos yacimientos de gas natural (Shebergan) y petróleo, aunque lo poco que se puede explotar casi en su cotalidad es exportado hacia Uzbekistán (no poseen refinerías); también cuenta con el 5 por ciento de las reservas mundiales de carbón.

Siendo así la situación cabe preguntarse, ¿Gracias a quésobrevive el pueblo afgano? Una de las principales fuentes de subsistencia y sobre todo en los últimos años, indiscutiblemente ha sido la ayuda humanitaria prestada a Afganistán por diferentes organismos internacionales y organismos no gubernamentales, con ayuda alimentaria, tiendas de campańa y atención médica. Pero la principal fuente de ingresos desafortunadamente es gracias al narcotráfico de drogas, opio $y$ heroína, se dice que la producción de estupefacientes se incrementa a partir de la intervención militar soviética en suelo afgano.

(...) “Hasta los 70 Pakistán es el primer productor mundial de opio pero no había producción local de herolna. También la historia del comercio de drogas en Asia Central está conectada a la acción encubierta de los servicios estadounidenses: en apenas dos años de actividad de la CIA, la frontera entre Afganistán y Pakistán se transforma en el primer productor mundial de heroína (Alf red McCoy, Drug fallount: the CIA's Forty Year Complicity in the Narcotics trade. The progressive; agosto 1997. En Pakistán la población drogadicta pasa del virtual cero de 1979 a 1,2 millones de 1985 . Como para el escándalo Irán-Contras, la CIA encuentra conveniente cerrar un ojo y financiar con el narcotráfico los mujahidin que utiliza en clave anticomunistan.

Diciembre 2001-Enero 2002, 
-Uno de los dramas de la polírica exterior de Estados Unidos y en los tíltimos años enfriará las relaciones con el tradicional aliado paquistano. Como escribe Giulietto Chiesa (G. Chiesa, 1 misteri dei Talibani, Limes, Roma 2001). los Estados Unidos están empeñados con la mano izquierda de la DEA - la Drug Inteligency Agency a deshacer lo que la mano derecha de la ClA ha tejido durante años. No lo consiguen - y a cambio la lucha al narcorráfico puede ser funcional a proyectos políticos - asi como no lo consiguen en otros escenarios, antes en Vietnam, hoy en Colombian.

"Hasta la llegada de los talibanes, Afganistán compite con Birmania en

UNDCP - Opium Poppy Growing Provinces in Afghanistan, 2000

Poppy area (hectares).

\begin{tabular}{|l|l|l|}
\hline Provincia & 1999 & 2000 \\
Badakhshan & 2.684 & 2,458 \\
Badghis & - & 41 \\
Baghlan & 1.005 & 199 \\
Balkh & 4.057 & 2,669 \\
Farah & 787 & 1,509 \\
Faryab & - & 36 \\
Helmand & 44,552 & 42,853 \\
Herat & - & 38 \\
Jawzjan & 2,593 & 746 \\
Kabul & 132 & 340 \\
Kapisa & 5 & 104 \\
Kunar & 288 & 786 \\
Kunduz & 38 & 489 \\
Laghman & 297 & 707 \\
Logar & 29 & 46 \\
Nangarhar & 22,990 & 19,747 \\
Nimroz & 203 & 219 \\
Oruzgan & 4,479 & 4,331 \\
Qandahar & 6,032 & 3,427 \\
Samangan & - & 54 \\
Takhar & 201 & 647 \\
Zabul & 611 & 725 \\
\hline Fur & & \\
\hline
\end{tabular}

Fuente: www.relief.int/w/map.nsf/ la producción de opio. En 1995 produce 220 toncladas por año. En 1997, con apenas un año de poder. trepa a dos mil 800 toneladas. Decenas de caravanas de Toyota todoterreno, con escoltas pesadamente armadas, salen varias veces por mes de las provincias productoras de Helmand y Kandahar con dirección a Pakistán. Es un tráfico muy bien organizado. Según la Undep - el programa de la ONU contra la droga - hay un millón de campesinos afganos empleados en la producción, para quienes no les queda más de el uno por ciento de las ganancias: 100 millones de dólares. Apenas otro 7.5 se pierde en las fases de intermediación, pero el 91,5 enriquece la criminalidad de los centros de consumo de los países "civilizadosn. Son más de 900 millones de dólares por año -sólo desde Afganistány se calcula que el 60 por ciento de este monto llega a Estados Unidosm.?

En 1999, el gobierno talibán supuestamente prohibió que se sembrara más amapola en Afganistán, y como muestra la tabla siguiente, efectivamente la producción ha bajado sustancialmente, aunque se rumora que esto sólo fue un acto de los talibanes para aminorar las criticas hacia su gobierno, pero que en realidad tienen reservas de goma de opio, que pueden satisfacer la demanda por lo menos durante 10 años. $\mathrm{A}$ continuación cuadro de producción de opio:

Como se desprende del cuadro anterior, la producción de opio disminuyó sustantivamente después de la prohibición decretada por el régimen Talibán, pero no lo suficiente, para eliminar el narcotráfico, esto lo saben los talibanes, pero aparte de que les beneficia, no le pueden proporcionar a los campesinos una fuente segura y abundante de recursos económicos para su sustento, igual que sucede en los paises andinos que producen la hoja de coca.

Una vez que tomaron el poder los talibanes en el año de 1997, la guerra civil continuó, cuestión que parece casi inexplicable, sobre todo cuando los talibanes ya para 1998 dominaban el 90 por ciento del territorio afgano, tenían el reconocimiento diplomático de sus vecinos, el apoyo financiero y humanitario. Algunos autores sostienen la hipótesis que después de 1998, la guerra se ha prolongado, entre las diferentes facciones armadas afganas por la lucha de tomar para sí las zonas más fértiles del pais, para poder sembrar amapola y apoderarse del lucrativo negocio del narcotráfico.

\section{Petróleo}

A partir de la Guerra del Golfo A pérsico, más que nunca se puso en claro que las sociedades globalizantes y globalizadoras, no pueden subsistir sin el oro negro. Lo másgravedel caso, es que de estas potencias las más industrializadas, por un lado son las que más consumen y por otro, no tienen o casi no producen petróleo. En el caso de los Estados Unidos, si bien es cierto que tiene petróleo ya casi no lo explota y lo conserva como reserva estratégica, si lo llegara a usar se supone no le duraría más de 30 años; éste país. para incrementar su reserva estratégica, le compra petróleo a México y para su consumo diario depende casi en su totalidad de las exportaciones de Arabia Saudita y Venezuela. Estados Unidos es el país que consume más petróleo en el mundo, se calcula que sólo ellos consumen el 25 por ciento $(833 \mathrm{mil}$ millones de toneladas mérricas) de todo el petróleo que se produce en el mundo. 
Afganistan geografia e historia

El petróleo es un recurso natural no renovable, las reservas petroleras de los países de los cuales se abastecc actualmente el mundo, tarde o temprano se agotarán. Una preocupación constante del gobierno de los Estados Unidos siempre ha sido conservar y prolongar el "American way of lifex, parte de ese modo de vida es el uso inmoderado del petróleo y sus derivados. Siendo una delas sociedades mejor organizadas y con una visión de abastecimiento de su economía a largo plazo, éste gobierno tienen como preocupación permanente la búsqueda de nuevas fuentes de abastecimiento de petróleo.

Por ello, inmediatamente que se derrumba el régimen soviético, los grandes consorcios petroleros de Estados Unidos apoyados por el gobierno, empiezan sus operaciones dirigidas a entablar contactos de negocios con los países ex soviéticos limítrofes con el Mar Caspio (Rusia, Uzbekistán, Tadjikistán, Turkmenistán), así como con otras ex repúblicas soviéticas del Asia Central como sería Azerbaiyán, Kazajstán y Kirguistán. Se sabe que ya para el ańo de 1998 las compañías petroleras norteamericanas habian firmado contratos que van más allá de los 100 mil millones de dólares, cifra que es un claro ejemplo del trabajo realizado por ellos y el interés que les merece la región.

(...) Se proyecta que la totalidad de reservas de petróleo existentes en $\mathrm{cl}$ litoral caspiano de los países de Irán, Kazajstán, Azerbaiyán, Turkmenistán y Rusia es de 24 mil millones de toneladas métricas; es decir el 15 por ciento del total de las reservas petroleras $\mathrm{del}$ mundo ( $\mathrm{y}$ un 50 por ciento de las reservas de gas natural)". ${ }^{10}$

El problema del petróleo y el gas natural del Mar Caspio y del Asia Central, es que no se puede transportar de forma rápida y fácil hacia el Occidente. Hasta el momento la única forma de transportarlo es a través de los oleoductos rusos, y como se

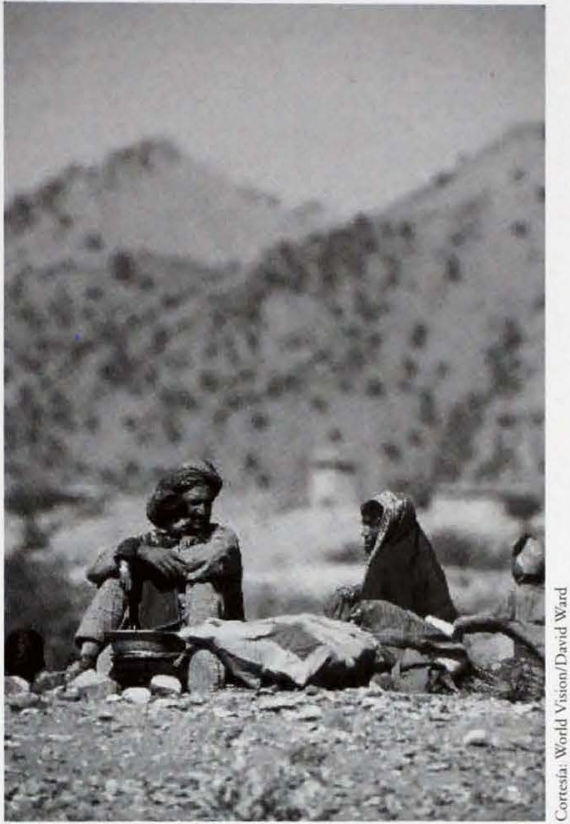

comprenderá, éste país reclama un alto porcentaje por su uso, ya que el gobierno ruso aduce que los oleoductos, los proyectaron. financiaron y construyeron ellos en la era soviética, por lo tanto tienen derechos. Dicha situación, indis-curiblemente no es del gusto de las repúblicas ex soviéricas y mucho menos de los países de Occidente; por ello, las compañias petroleras occidentales especialmente las norteamericanas han hecho todos los esfuerzos posible por salir de ese virtual monopolio del transporte del crudo y del gas natural del Asia Central.

Otro elemento que debe tomarse en cuenta, es la alta peligrosidad de la región, por la guerras civiles que se libran a la fecha, como por ejemplo. los movimicntos separatistas de Chechenia, el problema de Nagorno Karabaj (Georgia), que pone en peligro incluso los mismo oleoductos rusos, que atraviesan esos países hacia el puerto de Novorossisk y de ahí hacia Occidente. Es precisamente en éste esfuerzo por liberarse de los oleoductos rusos y sus condiciones. como de los peligros de la región del Cáucaso, que entra en la escena Afganistán, que dada su posición geogrifica mediterránea, sería la ruta ideal para construir oleoductos y gasoductos, que los transporten hacia Pakistin y de ahi directamente al Mar Indico.

Se sabe que la primera compañía petrolera en atreverse a proyectar la construcción de un oleoducto que pasará por Afganistán fue la Bridas de origen argentino. Su representante Bulgheroni, se pone en contacto con varios presidentes de la región. entre ellos la primera ministra de Pakistán Benazir Bhutto, los dirigentes de las facciones militares de Afganistán, el presidente de Turkmenistán Saarmurad Nijazov, se dice que todos y cada uno de ellos recibieron jugosas recompensas por autorizar los respecrivos permisos

Diciembre 2001-Enero 2002 
y concesiones para la construcción del oleoducto. Sin embargo, la compañía Bridas, después de estar bajo presión politico-diplomático, por varios meses por parte de agentes petroleros de Estados Unidos y la Gran Bretańa se retiro temporalmente del negocio.

(...) " De un día para ouro, en octubre de 1995, Nijazov sustituye la Bridas con la compañ́a estadounidense Unocal, detrás de la cual esta Henry Kissinger y que puede emplear la influencia del entonces presidente Clinton. Unica condición: la pacificación de Afganistán según el diseño paquistano que prevé la utilización de la carta talebanan."

Por ello los analistas internacionales del problema afgano. consideran que la compañía Unocal, en su momento financió al movimiento talibán no sólo para que tomará el poder sino para que el gobierno de Estados Unidos, no tomará medidas severas en su contra, cuando se inicio su política de violación de los derechos humanos en Afganistán ni por el cobijo que se le brindaba a Osama Bin Laden. Tuvo que ocurrir el 11 de septiembre para que Estados Unidos, por fin se "acordarán de la existencia de Afganistán, para ajustarle cuentas, pero olvidando que de forma directa ellos han sido los creadores y protectores de éste pais hasta que les fue útil a sus intereses.

\section{La guerra de medios}

\section{entorna}

entorno

entorns

entorna

entoring

entorno

entori

entor

entor

entorno

entorns

entoluo

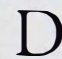

urante la guerra de Estados Unidos en contra de lrak en 1991, la llamada "Tormenta del desierton, bajo el argumento de defender a Kuwair de la invasión iraquí; éste de forma abierta censuró y monopolizó la información referente a dicha guerra, permitiendo que sólo el consorcio televisivo $\mathrm{CNN}$ tuviera los derechosexclusivosde transmisión. En los medios informativos se daba por sentado que lo que ellos transmitían ya venía edirado por el Departamento de Defensa, lo que significa una doble censura estatal. No se permitió que reporteros de guerra de ninguna agencia de noticias nacional e internacional estuviera en el frente, la opinión pública internacional se tuvo que conformar con lo que decía y como lo decía cl gobierno de los Estados Unidos a través de la CNN.

En la acrual guerra que libran los Estados Unidos en contra de Afganistán, se ha recurrido a la misma estrategia. La mayor parte de la población en el mundo, que no tiene acceso a los sistemas de televisión por cable y computadoras conectadas al Internet, se están conformando, con lo que transmiten y escriben sus medios de comunicación local, muchos de ellos en solidaridad con los Estados Unidos han aceptado transmitir única $y$ exclusivamente lo que proviene de la cadena televisiva de CNN y de otras televisoras norteamericanas. Se esta de nuevo ante una transgresión abierta e intencional, al derecho de información que tienen los pueblos del mundo. $\mathrm{Si}$ se ve éste hecho desde un punto de vista más analítico, estamos frente a un fenómeno de la manipulación de la opinión pública internacional, desde la óprica de los Estados Unidos y de acuerdo a sus intereses muy particulares.

La diferencia en la actual guerra en contra de Afganistán la está poniendo la agencia de noticias por satélite Al Jazeera. Esta agencia comenzó a transmitir su señal hace aproximadamente dos ańos, transmite especialmente para el mundo árabe y por ello el árabe que urilizan es estandarizado de tal manera que sea comprensible a todosesos pueblos. Esta televisora se ha distinguido, por ser un medio abierto a todas las opiniones, actores politicos y sociales así como a los diferentes paises del Cercano y Medio Oriente, razón por la que ha sido duramente criticada, pero a pesar de esas críticas ha seguido adelantc, ya que consideran que una de las razones deser de ésta televisora es precisamente el derecho a la información. ${ }^{12}$

Al Jazeera tiene los derechos exclusivos de transmisión de los reportajes de guerra desde territorio afgano, es la única agencia informativa que desde hace dos años tiene corresponsalía en Kabul. El 7 de octubre, horas después en que dieron inicio los bombardeos de Estados Unidos en contra de Afganistán, ésta agencia transmitió un mensaje de los voceros del Talibán y de Al Qaeda, que en su primera edición fue transmirida completa; pero fue editada so pretexto que los dirigentes talibanes y de al Qaeda estuvieran lanzando señales convenidas a sus seguidores en Estados Unidos, de ahí en adelante todas las noticias que transmite al Jazcera deben de ser analizadas minuciosamente. antes de que segmentos de ellas sean dados a conocer al público norteamericano y otros pueblos del mundo.

Por lo menos en Europa y en especial en Francia, de acuerdo a los datos proporcionados por la Televisión Alemana, se esta dando un boom en la instalación de pequeñas antenas parabólicas, de las personas con posibilidades económicas para instalarlas, el mismo fenómeno esta ocurriendo en los bares, cafés y restaurantes populares, pues la gente esta afluyendo especialmente para ver las noticias que transmite al Jazeera. Esta misma agencia's realizó una pequeña encuesta, y los telespectadores, dicen claramente que no quieren ver los noticicros de su pais y los transmicidos por la CNN y demás cadenas norteamericanas pues no están informando la verdad acerca de la guerra de Afganistán. El gobierno norteamericano ha perdido el monopolio de las noticias, no se sabe hasta el momento en qué medida, ésta pérdida impedirá esconder la realidad de los hechos.

La censura de los medios de comunicación por parte de los Estados Unidos en sus dos últimas guerras, no 


\section{PER - TURBANTE}

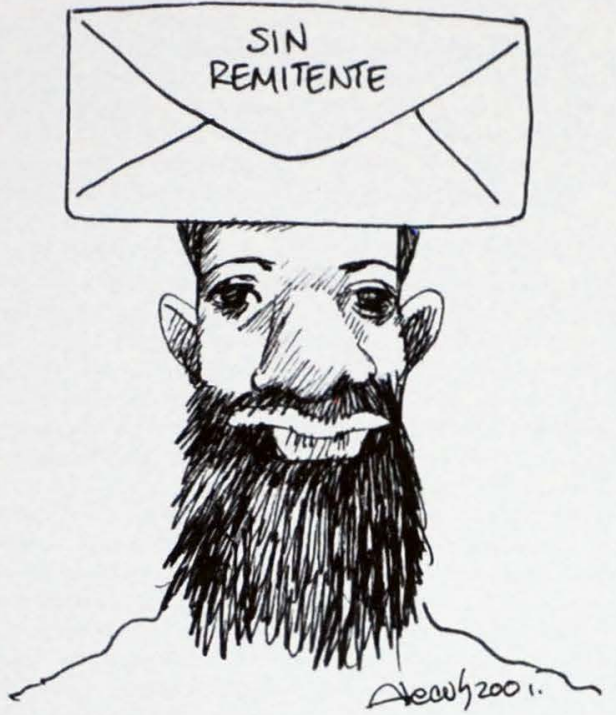

coincide con la posición norteamericana de ser los adalides en la defensa del derecho de expresión a nivel mundial; esmás cienen organizaciones de defensa de la libertad de expresión, que califican no sólo a los medios de comunicación norteamericanos, sino también a los larinoamericanos. El ciudadano común y corriente que no está al tanto de la historia y del curso de la política exterior de los Estados Unidos, podrá interrogarse, ¿por qué éste país censura sus medios?. El gobierno de los Estados Unidos para justificarse ha argumentado, que no pueden informar todo, porque ello pondría en peligro las misiones militares en el terreno enemigo. Sin embargo esa explicación deja muchas dudas.

Históricamente conviene recordar que éste pals, en aras de que no se expandiera el comunismo en el sudeste asiárico, y siguiendo al pie de la letra los posculados de su famosa "Doctrina del dominón" ${ }^{14}$, se involucró en Viet Nam, después que éste fue perdido por los franceses. Estados Unidos maquinó los incidentes del Golfo de Tonkín en el año de 1964 para involucrarse de lleno; la guerra duróde 1964 hasta 1975 . En éste conflicto Estados Unidos perdió más hombres que durante la Segunda Guerra Mundial, además los medios de comunicación masiva, en especial la televisión nacional y extranjera le dieron una amplia cobertura.

Los hogares norteamericanos se desayunaban, almorzaban y cenaban, con terribles escenas de guerra, de las barbaridades que cometía el ejército norteamericano con la población civil, con los masivos bombardeos; pero también veían los cuerpos destrozados de sus hijos, familiares, amigos y vecinos. Aunque no tenian la guerra fisicamente en su pais, la vivian y sufrian a través de las pantallas de sus televisores. Al final la opinión pública norteamericana terminó odiando esta guerra, obligaron a su gobierno a firmar la paz, lo que significó una derrota histórica para los Estados Unidos, que salió derrotado y humillado de Vier Nam.

Precisamente, a parrir de la amplia cobertura de los medios de comunicación, hay un impacto psicológico para el norteamericano medio, dando lugar al llamado «sindrome de Viet Namw, que consiste en el repudio a involucrarse en una guerra extraña y lejos. De aquí se deducen dos efectos: en primer lugar la acritud del pueblo norteamericano, de no firmarle a sus gobiernos cheques en blanco para involucrarse en guerras extranjeras, en donde no se sabe exacramente que es lo que se persigue, con el costo de la vida de muchos norteamericanos sin pena ni gloria. El segundo se refiere a la decisión del gobierno norteamericano de no dejar una coral libertad a los medios de comunicación masiva, en los conflictos futuros.

De la guerra de Viet Nam a la guerra del Golfo Pérsico, pasaron más de tres lustros, y el gobierno de los Estados Unidos suponia que el sindrome de Viet Nam habia sido superado; pero para curarse en salud, antes del inicio de la guerra militar propiamente dicha, en los meses que la antecedieron, se declaró una guerra de la información, cuyo objerivo principal a nivel externo, era convencer a la opinión pública internacional de la justeza de la intervención de los Estados Unidos en el conflicto entre Irak y Kuwait.

Recuérdese que Estados Unidos se involucró en ésta guerra so pretexto de la defensa de los derechos humanos violentados al pueblo de kuwaiti: sin embargo sus objetivos reales, eran asegurar el abastecimiento de petróleo barato para sí y para todo el mundo occidental, resquebrajar de una $v e<$ por rodas la frágil unidad del mundo árabe. detener las ambiciones hegemónicas de Irak en el Cercano y Mcdio Oriente; Diciembre 2001-Enero 2002 
desprestigiar el régimen y la imagen de Saddan Hussein, que los pueblos musulmanes y el resto del mundo creyeran que era un hombre cruel $y$ sanguinario, que de casualidad y después de muchas intrigas había accedido al poder. El problema central es que Saddan Hussein, se perfilaba como lider del mundo árabe; los analistas coinciden al señalar, que ambicionaba ocupar el sitial dejado vació por el extinto presidente egipcio Gamal Abdel Nasser.

Otro hecho importante es que en la guerra entre Irán e lrak (1980 1988), Estados Unidos y las potencias occidentales de forma ilegal armaron a éste último en cantidad y calidad de armas, con el objerivo de detener el avance del fundamencalismo iraní, en ese momento Saddan Hussein y su régimen servía a los propósitos de los EE.UU., por lo que no se le criticaba $y$ recibla ayuda a manos llenas.

En el nivel interno, era necesario tranquilizar a toda costa a la población norteamericana que no se iba a repetir otro Vietnam, que las operaciones en lrak iban a ser operaciones quirúrgicas, como las que se habían llevado a cabo en 1982 en Grenada y la invasión a Panamá en diciembre de 1989; es más el mismo nombre que se le dio a la operación "Tormenta del Desierton, es simbólica, una tormenta viene y se va, todos los medios de comunicación al unísono repetían lo mismo, para darle un mensaje de seguridad al pueblo norteamericano.

En la guerra contra Afganistán se ha urilizado el mismo método, desprestigiar por todos lo medios de comunicación nacional e internacional al régimen Talibán y a Osama Bin Laden; los medios han difundido estudios psicológicos de éste último y en general de cualquier terrorista, llegando incluso a decir que son psicópatas, personas acomplejadas, débiles mentales, resaltando todas las atrocidades cometidas por el régimen Talibán en contra de las mujeres y las niñas afganas. La cabeza de los dirigentes de A I Qaeda tienen precio, pululan a través de Internet supuestas biografias de Osama Bin Laden, en donde se recalca el hecho de que su familia y su pais lo han desconocido, olvidando los estrechos vínculos que han unido al régimen Talibán y Osama Bin Laden con los Estados Unidos, en especial con la Agencia Central de Inteligencia de ese pais en la década de los 80 del siglo XX.

Seles olvida mencionar asimismo, que el rompimiento definitivo entre Osama Bin Laden y los Estados Unidos, se produce a raíz del establecimiento de bases militares norteamericanas en varios países árabes del Golfo, entre ellos Arabia Saudita, patria de Bin Laden. Además se ha ignorado un aspecto importante de la psicología de estos pueblos, la mayoría de los creyentes del Islam en el mundo árabey no árabe, fundamentalista o no, ven estas acciones como una profanación a los lugares más sagrados del Islam, la Meca y Medina.

Otroelemento importante en esta guerra de medios, es la actitud desafiante del gobierno Talibán, que a través de la televisora $\mathrm{Al}$ Jazeera, denuncian los daños colaterales como eufemística Estados Unidos llama los destrozos que producen sus bombas inteligentes, supuestamente lanzadas a objetivos militares talibanes $y$, que lamentablemente han impactado barrios populares, los depósitos de la Cruz Roja Internacional, oficinas de la Organización de Naciones Unidas. $\mathrm{T}$ an importante es la televisora $\mathrm{Al}$ Jazeera, que los propios representantes del gobierno de Estados Unidos como Collin Powell y Condoleeza Rice, han transmitido entrevistas pagadas, para su difusión en el mundo árabe $y$ musulmán.

El lunes 29 de octubre, convocó a una rueda de prensa el nuevo jefe del Departamento de Seguridad Nacional $y$ un vocerodel $\mathrm{FBI}$, para informarle a los medios que según los indicios que se tienen en las próximas semanas, era inminente un nuevo ataque terrorista dentro del territorio norteamericano. Para mantener la seguridad, se habían desplegado 125 mil policías adicionales, pero no se ofrecieron mas datos que aclaren dicha situación; creando de esa forma un mayor estrés y un ambiente de pánico en el pueblo norteamericano. Uno de los últimos actos en esta guerra de medios se dio el 7 de octubre, cuando el gobierno paquistaní ordenó sin mayores explicaciones, el cierre del consulado de Afganistán en Karachi, desde donde habitualmente los embajadores talibanes a través de ruedas de prensa han estado informando lo que está sucediendo al interior de Afganistán.

En esta ocasión la guerra de medios se disputa desde varios ámbitos; los talibanes con la cobertura que tienen con Al Jazeera que esta monopolizando al público, por lo menos al europeo y del mundo árabe $y$ musulmán que prefieren ver y escuchar éste canal; Estados Unidos a través de la CNN, la Voz de las Américas (VOA) $y$ todos los medios en Occidente que se le han querido unir $y$, por último de codas aquellas personas que tiene acceso a la red de Internet y prefieren leer periódicos y revistas electrónicos alternativos, porque a través de ellos están siendo mejor informados.

\section{Bibliografía básica}

Cabrera, Enriquera y' Camacho, José Luis (Comp.). Golfo Pérsico. Visiones y Reflexiones. Mexico, El Dia en libros, 1991.

Hodara, Joseph. ISRAEL. MÉxico, UNAM, 1986. Col. Grandes Tendencias Politicas Contemporáneas.

Pelayo. Fernández, Cristina. PAKISTÁN, BANGIADESH y SRI LANKA. MExico, UNAM. 1985. Col. Grandes Tendencias Politicas Contemporáneas.

Preciado Solis, Benjamin. INDIA. La democracia más grande del mundo. México. UNAM. 1986. Col. Grandes Tendencias Politicas Contemporáneas.

Quintana Pali, Santiago. AFGANISTAN. Encrucijada estratégica del Asia Central. Mexico. UNAM. 1986. Col. Grandes Tendencias Políticas Contemporáneas.

Quintana Pali, Sanciago. IRAN. Islam y nacionalismo. Mexico, UNAM, 1986. Col. Grandes Tendencias Politieas Contemporáneas.

Zeraoui, Zidane. ARGELIA - LIBIA: IsJam y Socialismo. México. UNAM. 1986. Col. Grandes

Tendencias Polfticas Contemporáneas. 